\title{
Trajetória de um Curso de Licenciatura em Computação no Interior do Paraná
}

\author{
Maytê Gouvêa Coleto Bezerra ${ }^{1}$, Carlos Roberto Beleti Junior ${ }^{1}$, Robertino Mendes \\ Santiago Junior ${ }^{1}$, Alexandre Prusch Züge ${ }^{1}$
}

${ }^{1}$ campus Avançado de Jandaia do Sul - Universidade Federal do Paraná (UFPR)

Rua Dr. João Maximiano, 460 - 86.900-000 - Jandaia do Sul - PR - Brasil

\{mayte, carlosbeleti, robertino, alexandrezuge @ufpr.br

\begin{abstract}
Among the multiple increasing and spreading efforts of public higher education in Brazil, the Federal University of Paraná (UFPR) created an advanced campus in the city of Jandaia do Sul (PR). In 2014, the Teaching Degree in Computer Science course started its activities, going through a curricular reform, in force since 2016, obtaining good results in institutional (MEC) and student (ENADE) assessments. This text presents the history of the first seven years of the UFPR Teaching Degree in Computer Science course in Jandaia do Sul, describing its conception, pedagogical reformulation, physical structure, information about the students' training possibilities, challenges and difficulties faced, in addition to the efforts to remedy them and the merits achieved.
\end{abstract}

Resumo. Dentre os múltiplos esforços para ampliação e interiorização do ensino superior público no Brasil, a Universidade Federal do Paraná (UFPR) criou um campus avançado na cidade de Jandaia do Sul (PR). Em 2014, o curso de Licenciatura em Computação (LC) iniciou suas atividades, passando por uma reformulação curricular, vigente desde 2016, obtendo bons resultados em avaliações institucionais (MEC) e estudantis (ENADE). Este texto apresenta a história dos sete primeiros anos do curso de LC da UFPR em Jandaia do Sul, descrevendo sobre sua concepção, reformulação pedagógica, estrutura fisica, informações sobre as possibilidades formativas discentes, desafios e dificuldades enfrentadas, os esforços para saná-los e os méritos alcançados.

\section{Introdução}

A partir do ano de 2003, o Governo Federal instituiu políticas públicas que visavam reduzir desigualdades sociais, sobretudo em relação ao acesso a cursos de ensino superior. Uma das ações foi o aumento do número de vagas ofertadas na rede federal, por meio do Programa Nacional de Expansão das Universidades Públicas Federais, possibilitando que fossem construídos campi universitários no interior dos estados [Lubambo e Bastos, 2013; Nascimento, 2013].

O processo de interiorização, especialmente, na Universidade Federal do Paraná (UFPR), desencadeou-se em 1993, com a instalação do campus Palotina [Corrêa e Nascimento, 2017]. Posteriormente, passou-se à ampliação dos cursos ofertados no campus Pontal do Paraná e, em 2005, à criação do campus Matinhos. Os esforços mais recentes da UFPR no processo de interiorização contaram com a criação do campus avançado de Jandaia do Sul, em 2013, e do campus de Toledo, no ano de 2014, além do lançamento de um polo de Educação a Distância em Terra Roxa, em 2020. 
Especificamente, o campus em Jandaia do Sul (PR) iniciou suas atividades em 2014, com a implantação concomitante de cinco cursos de graduação, a saber: Licenciatura em Computação, Licenciatura em Ciências Exatas, Engenharia Agrícola, Engenharia de Alimentos e Engenharia de Produção.

A cidade escolhida para a implantação, hoje com 68 anos, localiza-se na região Norte do Paraná e é considerada um "centro comercial urbano de menor importância", distando cerca de 10 a $15 \mathrm{~km}$ de outras de cidades de porte semelhante, mas entre cidades de maior estrutura, no caso Londrina e Maringá que, por sua vez, deveriam estar a cerca de 100 quilômetros de distância, cumprindo a política da Companhia Melhoramentos Norte do Paraná que organizou a ocupação da região [Moreira 2007, p. 22].

O município já contava com uma faculdade privada e sem fins lucrativos, local em que se deu a instalação provisória do campus da UFPR. De início, portanto, parte do prédio foi alugado, comportando uma estrutura mínima, visando o princípio das atividades didáticas e, paulatinamente, mais espaços, nas instalações compartilhadas com a faculdade particular, passaram a ser alugados e reformados para comportar o funcionamento completo dos referidos cursos. No princípio, havia um projeto para a construção de sede própria em terreno doado, no entanto, não foram recebidos recursos financeiros para a sua execução.

O presente artigo trata especificamente sobre o desenvolvimento do curso de Licenciatura em Computação (LC), no campus em Jandaia do Sul da UFPR. Assim, o trabalho em tela se propõe a compartilhar os esforços na implantação do curso, bem como a apresentar os méritos alcançados e as dificuldades enfrentadas, colaborando para os avanços de cursos correlatos no país e, consequentemente, contribuindo na defesa do ensino de Computação na Educação Básica.

O texto conta com uma síntese da concepção do curso, das modificações realizadas em seu Projeto Pedagógico e da infraestrutura, das opções de formação complementar propiciada aos estudantes e, além disso, avança para uma discussão acerca dos desafios enfrentados para sua constituição e consolidação.

\section{Projeto pedagógico e estruturação do curso}

Na implantação do curso de LC em Jandaia do Sul, o Projeto Pedagógico do Curso (PPC) foi elaborado com base no Currículo de Referência para Cursos de LC [SBC 2002], no Parecer CNE/CES 136/2012, no que tange a especificidade das licenciaturas [MEC 2012], e em currículos de cursos relacionados.

O PPC foi inicialmente pensado para conviver em harmonia com os demais cursos do campus, prevalecendo o compartilhamento de recursos humanos e materiais. O projeto original contemplava uma carga horária total de 2918 horas, sendo composta por 2124 horas de conteúdos curriculares obrigatórios, 414 horas de estágio supervisionado, 72 horas de trabalho de conclusão de curso, 108 horas de conteúdos optativos e 200 horas de atividades formativas.

Entretanto, por conta dos esforços de coexistência com os demais cursos, havia no PPC, de um lado, disciplinas que não tinham correspondência nos documentos de referência para cursos de LC; e de outro, havia lacunas no que se remetia à abordagem de conteúdos disciplinares importantes para a área da Computação na atualidade. 
Motivado pela publicação da Resolução CNE/CP 2/2015 [MEC 2015], a qual trata sobre as Diretrizes Curriculares Nacionais para a Formação Inicial e Continuada dos Profissionais do Magistério da Educação Básica, e pela modernização e atualização dos componentes curriculares do curso, o Núcleo Docente Estruturante (NDE) deu início ao processo de reformulação do projeto do curso já no ano de 2015.

O NDE considerou, ainda, para o processo de reformulação, propostas pedagógicas e de grades curriculares de cursos de LC e Licenciatura em Informática já consolidados no país, os quais possuíam notas 4 e 5 nos indicadores de qualidade CPC Conceito Preliminar de Curso ou CC - Conceito de Curso, disponibilizados pelo MEC.

Dessa forma, uma segunda versão do PPC [UFPR 2015] foi aprovada e está vigente desde 2016. As principais diferenças entre o PPC original e o novo [UFPR 2015] residem em uma modificação no caráter estritamente teórico dos componentes curriculares que passaram a ser combinados com a prática pedagógica e também com aplicações nas mais variadas áreas da Ciência da Computação.

Para a incorporação das práticas pedagógicas que, em função da nova legislação, tiveram sua carga horária aumentada para 756 horas, adotamos a estratégia de criar oito disciplinas, distribuídas uma em cada semestre do curso, no intento de sempre compor disciplinas teóricas da Computação à reflexão e aprofundamento de suas aplicações nos fazeres educativos de um licenciado da área.

Assim, o PPC atual resultou em uma carga horária total de 3260 horas, sendo que as disciplinas obrigatórias somaram 2430 horas, o conteúdo optativo foi aumentado para 144 horas e as cargas horárias de estágio, TCC e atividades formativas se mantiveram iguais. $\mathrm{O}$ tempo de integralização do curso permaneceu de 4 a 6 anos.

Além dos componentes curriculares já presentes no PPC, conceitos e estratégias de ensino como Pensamento Computacional e Computação Desplugada foram incorporadas às ações e atividades propostas por professores, e implementadas pelos alunos, dada a relevância de tais assuntos para a área, conforme preconizado em pesquisas de ensino [Lopes et al. 2020; Jesus et al. 2019; Rodrigues et al. 2018].

A fim de proporcionar aos estudantes uma melhor vivência do estágio obrigatório, o respectivo regulamento foi alterado para permitir um leque maior de campos de estágios, incluindo: entidades de direito público e privado, instituições de ensino, profissionais liberais, comunidade em geral e até unidades internas da UFPR. Essa alteração permitiu que parte do estágio dos discentes pudesse ser feita, por exemplo, em empresas da região, desde que estivessem em consonância com a definição do perfil do profissional egresso.

Vale lembrar que a licenciatura é comumente relacionada, de modo estrito, à formação de professores. Todavia, sabemos que a formação oferecida inclui a formação do educador no sentido amplo, portanto, habilitando para a função de educador social, educador em museus, para a produção editorial no campo da Educação, entre outras tantas. E, especialmente no caso da LC, não só, pois abrem-se muitíssimas outras áreas de atuação como a educação nas organizações, a gamificação na educação, a educação a distância e, até mesmo, a idealização e gerenciamento de escolas de cursos livres de informática, programação, robótica, produção de conteúdo web, entre outros.

Outra alteração realizada visando, entre outros aspectos, a ampliação da oferta de estágios foi em relação ao período do curso. Inicialmente, o curso de LC era ofertado no 
período matutino. Entretanto, a oferta de disciplinas neste período acarretava na diminuição das possibilidades de os estudantes viabilizarem seus estágios obrigatórios, haja vista que, no município de Jandaia do Sul, as aulas dos ensinos fundamental e médio ocorrem nos períodos matutino e noturno. Portanto, a partir do ano de 2019, as aulas do curso começaram a ser ofertadas no período vespertino. Cogitou-se a mudança para o noturno, no entanto, atentando-se ao forte incentivo e a participação maciça dos estudantes em atividades de pesquisa e extensão, optou-se por mantê-lo à tarde.

Por ser um curso novo, parte importante de sua consolidação advém da aprovação na avaliação do MEC. Nesse sentido, o curso recebeu em março de 2017 a visita "in loco" dos avaliadores, com a finalidade de realizar seu processo de reconhecimento. Os avaliadores consideraram que o curso apresentava um perfil muito bom de qualidade, atribuindo como conceito final a nota 4 .

Outro passo substancial deu-se na realização do Exame Nacional de Desempenho dos Estudantes (Enade), em 2017, quando cinco estudantes realizaram a prova, obtendo o conceito máximo. Em 2020, ano em que cursos de LC deveriam ser avaliados novamente, as provas do Enade foram suspensas devido à pandemia do COVID-19.

Ambos resultados descritos, tanto da avaliação do MEC como no Enade, foram entendidos pela equipe como bastante promissores, considerando que, segundo os dados do Sistema e-MEC, apenas 37,21\% dos cursos de LC ou Licenciatura em Informática, ofertados na modalidade presencial, possuem notas 4 ou 5 no Conceito de Curso ou Conceito Preliminar de Curso. Em relação ao Conceito Enade, apenas 9,30\% dos referidos cursos presenciais possuem conceito máximo 5 .

Ao longo dos anos, também houve incremento na estrutura física e material do curso. Atualmente, a LC conta com quatro salas de aula, um laboratório para as disciplinas de prática pedagógica, uma sala para a coordenação de curso, uma sala para um dos projetos de Extensão, além de vasta estrutura compartilhada como laboratórios de informática, laboratório Maker, salas de monitoria, sala de extensão, biblioteca, diversas salas administrativas e gabinetes para docentes, organizados em duplas ou trios. Podemos citar, também, materiais e equipamentos que ficam à disposição de docentes e discentes tais como tablets, notebooks, lousas digitais, sistemas de resposta à audiência e kits de robótica, eletrônica e Arduino.

No que se remete ao corpo docente, todos os professores efetivos atuam em regime de 40 horas com dedicação exclusiva. Quanto à titulação, 76\% são doutores e doutoras e os demais se encontram em processo de doutoramento.

\section{Atividades extracurriculares}

Sendo o tripé universitário formado pelo ensino, pesquisa e extensão e, visando possibilitar atividades formativas extracurriculares para os estudantes, projetos de ensino, extensão e de pesquisa foram propostos nas áreas de atuação dos docentes do curso. Quanto a programas e projetos de estímulo à docência, portanto voltados para as licenciaturas em geral, indicamos que, apesar da impossibilidade de participação no curso no Programa Institucional de Bolsas de Iniciação à Docência (PIBID), o programa Licenciar $^{1}$ acolheu nossos discentes desde 2014.

\footnotetext{
${ }^{1}$ Disponível em: http://www.prograd.ufpr.br/portal/coafe/uaf/licenciar/.
} 
Salienta-se que, diversos desses projetos ofereceram, inclusive, bolsas institucionais para que os alunos pudessem, além de se beneficiar com as oportunidades de capacitação mais completa, ter uma renda durante sua participação.

Em geral, os estudantes participantes desses projetos, sobretudo bolsistas, tendiam a permanecer no curso e obter melhor aproveitamento nas demais atividades, como as próprias disciplinas. Outro diferencial era a possibilidade de atuar com as comunidades atendidas pelos projetos, vivenciando a realidade local e experimentando-se como docentes em práticas pedagógicas propiciadas pelas intervenções extensionistas desde o início do curso.

Em um levantamento, por meio dos coordenadores dos projetos extensionistas e projetos Licenciar, por exemplo, calcula-se que, de 2014 a 2020, aproximadamente 50 bolsas foram oferecidas para os estudantes do curso de LC, cada uma com tempo médio de duração de 8 meses, além das participações na modalidade de voluntário. Ao total, entre bolsistas e voluntários, foram mais de 90 estudantes da LC atuando nesses projetos. Já em projetos de pesquisa, atingiu-se no curso 21 bolsistas de Iniciação Científica e Iniciação Tecnológica e 22 voluntários.

Outra oportunidade de atuação para os estudantes foi o Programa de Iniciação à Docência (PID) e o Programa de Iniciação à Monitoria (PIM). Nessas iniciativas, os discentes puderam atuar como monitores de disciplinas já cursadas por eles e, grande parte dessas atuações, foram remuneradas por meio de bolsas institucionais. Durante o período, pelo menos 14 discentes participaram destes programas.

Como ilustra o alto número de atividades, seja extensão, pesquisa ou no incentivo à docência, nota-se que tais oportunidades foram oferecidas e desfrutadas, em grande parte, mais de uma vez por um mesmo discente ao longo do curso. Ou seja, dependendo do interesse, foi possível obter experiência nas três frentes ou ainda aprofundar-se, participando de mais ações ou mesmo estendendo sua participação em um dado projeto.

Ademais, o curso pôde, por meio de editais institucionais de mobilidade acadêmica, proporcionar aos estudantes chances de realizarem intercâmbio. Em 2019, tivemos 2 discentes que participaram de intercâmbio em Portugal, em cursos na área da Computação; Licenciatura em Engenharia Informática no Instituto Politécnico de Tomar e Licenciatura em Ciências da Computação na Universidade do Minho.

Todas essas vivências propiciadas aos estudantes, além do enriquecimento de sua própria formação, foram, de certo modo, incentivos para a permanência no curso, bem como a continuidade nos estudos em programas de pós-graduação e atuação no mercado profissional nas áreas da Tecnologia e Educação. Assim, dos 16 alunos formados pelo curso, 3 já iniciaram em programas de mestrado em universidades públicas e grande parte dos demais prosseguiu trabalhando nas áreas.

Outra iniciativa que visava o engajamento estudantil foi a realização e a participação em eventos, dos quais destacamos aqueles institucionais: as edições locais do Festival Latino-americano de Instalação de Software Livre (FLISoL), promovidas anualmente entre os anos de 2014 e 2018; as 3 edições do Simpósio de Licenciaturas em Ciências Exatas e em Computação (SLEC) da UFPR (2016, 2018 e 2019), promovidas pelo campus de Jandaia do Sul, setor Palotina e campus Pontal do Paraná; as Semanas Acadêmicas dos cursos, promovidas no ano de 2019; as 3 realizações da Hora do Código; 3 participações em edições da Semana Nacional da Ciência e Tecnologia (SNCT). 
Tivemos ainda publicações em periódicos e eventos de relevância nacional na área da Computação e Educação com autoria de alunos do curso.

Recentemente, durante o período de quarentena devido à pandemia do coronavírus, com a finalidade de aproximar, mesmo que "virtualmente" a comunidade universitária, favorecendo a manutenção de vínculo dos estudantes com o curso e com a instituição, foi desenvolvida a iniciativa denominada \#COMPapo, a qual consistiu na realização de uma série de transmissões ao vivo - lives - na plataforma Instagram, por meio do perfil da LC (https://www.instagram.com/ufpr_lc/), tratando de assuntos que se relacionaram à Tecnologia, Computação, Educação e ao combate à COVID-19, bem como às vivências durante a quarentena como o ensino remoto emergencial e a prática de home office. Para tanto, participaram docentes e recém-formados no curso, além de profissionais convidados.

\section{Desafios para o curso de LC}

Os principais desafios que vêm sendo enfrentados para a consolidação do curso de LC, em Jandaia do Sul, remetem-se às questões da baixa entrada discente e da escassa formação de egressos.

De forma geral, os cursos ofertados no campus, até pelo caráter recente, possuem pouca procura no vestibular comparados a cursos de instituições de grandes centros. Todavia, acreditamos que a LC apresenta peculiaridades que devem ser analisadas.

Assim, tem-se que, apesar de passados mais de vinte anos da criação do primeiro curso de LC no Brasil e da sequente proliferação de tais cursos ao longo do território nacional, o curso ainda carece de muito reconhecimento social como relevante área de conhecimento e como profissão.

Para além do desconhecimento sobre sua existência, infelizmente, quando se distingue sua especificidade enquanto licenciatura, dentre os demais cursos de bacharelado ou tecnologia da área da Computação, herda à sua imagem a desvalorização associada às profissões da Educação que marca, infelizmente, nossa experiência atual, ao menos no cenário brasileiro.

Não obstante, conforme explanado por [Falcão et. al 2018], apesar da existência de iniciativas de inserir os conceitos computacionais na educação básica brasileira, a Computação ainda não é considerada um componente curricular, mesmo após a construção e homologação da Base Nacional Comum Curricular (BNCC).

A esse respeito, a despeito de iniciativas como a nota técnica da SBC [SBC 2018], em que é manifestada a discordância e críticas em relação às versões homologadas da BNCC e o Currículo de Tecnologia e Computação [Raabe et. al 2018], observa-se que a ausência da Computação como disciplina na educação básica prejudica a atuação profissional dos egressos da LC. Tal insegurança quanto à empregabilidade pode diminuir o interesse prévio dos estudantes em ingressar no curso.

Especificamente na LC, a cada ano são ofertadas 50 vagas, porém, como mostra a Figura 1, o ingresso bem como o número de formandos aparece bem abaixo dessas possibilidades. Observamos que a turma de 2017 teve sua conclusão prejudicada em função da suspensão do calendário acadêmico, em razão da pandemia em 2020. 


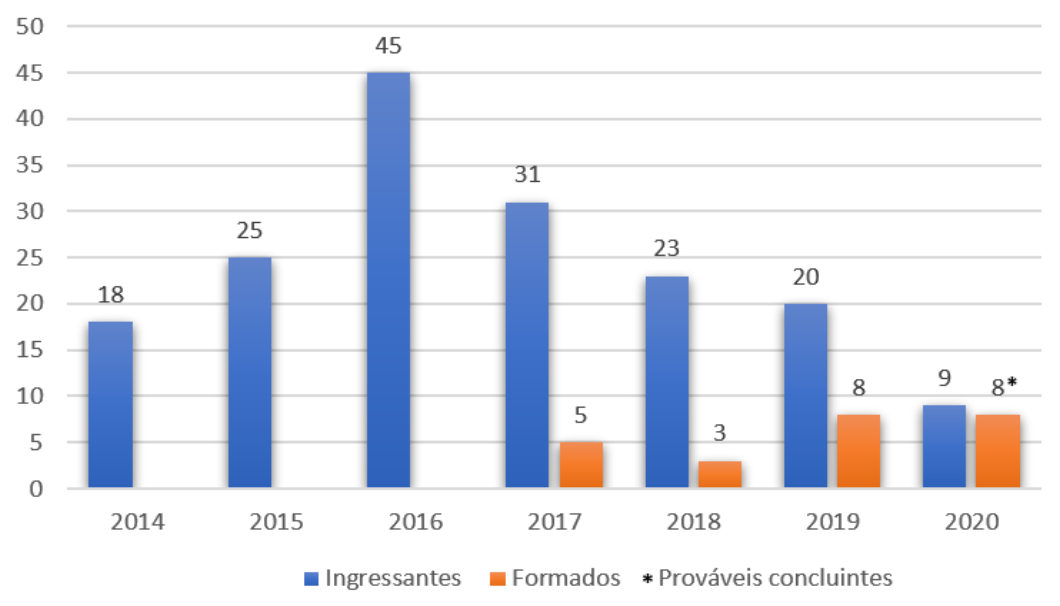

Figura 1 - Quantidade de estudantes ingressantes e formados por ano.

Ao observarmos qualitativamente os dados referentes à matrícula e conclusão do curso, constatamos um maior número de estudantes do gênero masculino, chegando a $82,46 \%$, frente aos $17,54 \%$ das estudantes, quanto ao número total de ingressantes. No entanto, quando comparamos o número de estudantes formados em relação ao gênero, temos que essa diferença diminui, chegando a taxa de $43,75 \%$ de egressas mulheres para $56,25 \%$ de homens.

Visando mitigar o baixo interesse inicial das meninas pela área da Computação e outras profissões das Ciências Exatas, existem ações de incentivo ao ingresso e permanência de mulheres no curso, tais como o edital CNPq/MCTI N ${ }^{\circ}$ 31/2018 - Meninas nas Ciências Exatas, Engenharias e Computação, contemplado pelo grupo Manna Team do Departamento de Informática da Universidade Estadual de Maringá [Flôr et al. 2020], que possui parceria com projeto de extensão de docentes do curso de LC. Como parte das ações desse projeto no campus, meninas discentes da LC participaram como equipe executora, inclusive com o auxílio, por meio de bolsa estudantil, coordenando atividades com meninas e professoras, também bolsistas, de dois colégios públicos, um de Jandaia do Sul e outro de Apucarana. Assim, foram realizadas ações de capacitação em diversas áreas de atuação do curso, ensino e divulgação da Computação, contribuindo para que meninas e mulheres tenham interesse em desenvolver estudos e pesquisas, bem como em seguir carreira profissional na área.

Já sobre os índices de evasão, conforme descrito em pesquisas a tal respeito em cursos da área da Computação [Rodrigues et al. 2015; Palmeira e Santos 2014], e especificamente de cursos de LC [Krzyzanowski et al. 2019; Hoed 2016; Florencio 2015], temos, no curso, que o quantitativo de estudantes evadidos chegou a $61,4 \%$ do total, percentual que apesar de alto e preocupante, se revelou menor, em média, que o mesmo curso em outras instituições como demonstrou [Florencio 2015].

Uma importante iniciativa, que se reflete na diminuição da evasão, diz respeito ao enfrentamento dos problemas de permanência vivenciados pelos discentes. Nesse sentido, a instituição tem oferecido, desde o início, por meio da Pró-Reitoria de Assuntos Estudantis (PRAE), editais de assistência para estudantes cotistas e em situação de fragilidade financeira, fornecendo auxílio moradia, permanência e refeição. Especificamente, para os alunos da LC, no campus foram contabilizados 30 estudantes beneficiados com esses auxílios de 2014 a 2020. 
Outrossim, conhecer as informações sobre os discentes do curso e taxas de reprovação em determinadas disciplinas, como realizado em trabalhos de pesquisa com nossos discentes [Krzyzanowski et al. 2019; Guedes et al. 2018], puderam nos orientar quanto às possíveis motivações do abandono e às possibilidades de como combatê-lo.

Além disso, objetivando a promoção da melhoria do desempenho acadêmico de todos os discentes, há implantado no curso, o Programa de Orientação Acadêmica, o qual ocorre mediante o acompanhamento e orientação por parte de todos os docentes do curso. No início de cada ano letivo, um docente é atribuído como orientador para cada turma. Na prática, ele acompanha os discentes da turma, auxiliando-os desde a realização da própria matrícula, como encaminhando-os quanto às melhores escolhas curriculares frente aos interesses de cada um, e até acolhendo questões de ordem pessoal, que podem acarretar ao encaminhamento pedagógico, psicológico ou assistencial.

\section{Considerações finais}

Por se tratar de um curso novo em um campus novo, recém implantado, houve muito trabalho árduo até a presente data. Em seu princípio, o curso carecia de infraestrutura física e de materiais. Entretanto, diversos investimentos foram realizados durante este período, como a aquisição de bibliografia, estruturação de laboratórios didáticos e pedagógicos, gabinetes de coordenações e docentes, salas para projetos de pesquisa e extensão, salas para monitorias, entre outros.

Outra dificuldade encontrada, em relação ao pouco tempo de existência do curso e do campus, foi a quantidade de alunos ingressantes que, aliada à alta evasão, tem implicado em uma quantidade pequena de alunos formados a cada ano.

No entanto, salientamos as iniciativas propostas pelos docentes do curso que, cientes da necessidade e relevância do curso, devido à irreversível relação estabelecida pela sociedade com a Computação e a Tecnologia, propuseram ações extracurriculares, tal como a oferta de projetos de ensino, pesquisa, extensão e programa de monitoria - que possibilitaram a atuação de mais de 145 estudantes, entre voluntários e bolsistas -, além da adequação do PPC conforme necessidades locais, incentivo à inserção e permanência de meninas e mulheres na área, acordos interinstitucionais com universidades no país e no exterior, parcerias com instituições escolares da região, realização e participação de eventos, intervenções pedagógicas, entre outras propostas que visavam motivar e engajar os estudantes no curso e, consequentemente, em sua conclusão.

Compreendemos os desafios de se conseguir uma maior participação do curso de LC nas esferas sociais e acadêmicas; do reconhecimento da atuação do profissional licenciado em Computação, bem como da compreensão, por parte dos docentes que atuam no curso, sobre sua importância para o cenário educacional; e, por alcançarmos uma maior participação das mulheres no curso, conforme proposto por [Oliveira et al. 2020].

Também estamos atentos às pesquisas sobre cursos correlatos à Licenciatura em Computação e às demandas contemporâneas de uma sociedade em constante evolução, corroborando com concepções como as descritas em [Falcão et al. 2018], tendo a convicção de que, a educação e a sociedade têm muito a se beneficiar com a Educação em Computação, a ser realizada desde os anos iniciais escolares até a graduação, e que os cursos de Licenciatura em Computação/Informática e afins são essenciais neste cenário. 


\section{Referências}

Corrêa, R. L. \& Nascimento, D. E. do. (2017). A interiorização das universidades e o mercado de trabalho regional: o caso da Universidade Federal do Paraná. Trabalho \& Educação, 26(2), 149-169. $\quad$ Recuperado de https://periodicos.ufmg.br/index.php/trabedu/article/view/9623.

Falcão, T., Araújo, D., França, R., Andrade, E., \& França, C. (2018). Currículo da Licenciatura em Computação: uma Proposta Alinhada às Novas Diretrizes e Demandas Contemporâneas. Anais dos Workshops do Congresso Brasileiro de $\begin{array}{llll}\text { Informática } & \text { na } & \text { Educação, } & 7(1),\end{array}$ doi:http://dx.doi.org/10.5753/cbie.wcbie.2018.1108.

Flôr, D., da Cruz, E., Possebom, A., Beleti Junior, C., Hübner, R., Gonçalves, P., da Silva, C., \& Aylon, L. (2020). MannaAcademy: impulsionando o protagonismo feminino através de uma rede interinstitucional de extensão universitária. In Anais do XXVIII Workshop sobre Educação em Computação, (pp. 26-30). Porto Alegre: SBC. doi:10.5753/wei.2020.11123.

Florencio, F. G. (2015). Evasão no curso de licenciatura em computação da universidade de Brasília. 83 f., il. Monografia (Licenciatura em Ciência da Computação)Universidade de Brasília, Brasília.

Guedes, K., Beleti Junior, C., \& Mendes Santiago Junior, R. (2018). Dificuldades no ensino de Algoritmos para o curso de Licenciatura em Computação: uma investigação inicial. Anais do Computer on the Beach, 0, 893-895. doi:https://doi.org/10.14210/cotb.v0n0.p893-895.

Jesus, A., Silveira, I., \& Palanch, W. (2019). Desenvolvimento do Pensamento Computacional por Meio da Colaboração: uma revisão sistemática da literatura. Revista Brasileira de Informática na Educação, 27(02), 69. doi:http://dx.doi.org/10.5753/rbie.2019.27.02.69.

Krzyzanowski, L., Beleti Jr, C., Santiago Jr, R., \& Tostes, R. (2019). Ensino de programação: um estudo preliminar nos cursos de licenciatura em Computação no Brasil. Anais dos Workshops do Congresso Brasileiro de Informática na Educação, 8(1), 21. doi:http://dx.doi.org/10.5753/cbie.wcbie.2019.21.

Lopes, A., Santana, T., \& Braga, A. (2020). O ensino de pensamento computacional por meio de jogos desplugados e olimpíadas científicas: um relato de experiência nos anos finais do ensino fundamental. In Anais do XXVIII Workshop sobre Educação em Computação, (pp. 96-100). Porto Alegre: SBC. doi:10.5753/wei.2020.11137.

Lubambo, C. W., \& Bastos, I. A. C. F. (2013). Condições favoráveis à interiorização das universidades públicas em Pernambuco. RMP-Revista dos mestrados profissionais, 2(2). Recuperado

de https://periodicos.ufpe.br/revistas/index.php/RMP/article/view/507.

MEC (2015). Diretrizes Curriculares Nacionais para a formação inicial em nível superior (cursos de licenciatura, cursos de formação pedagógica para graduados e cursos de segunda licenciatura) e para a formação continuada. Resolução CNE/CP 2/2015. Recuperado de http://portal.mec.gov.br/revalidacao-de-diplomas/323-secretarias112877938/orgaos-vinculados-82187207/21028-resolucoes-do-conselho-pleno-2015. 
MEC (2012). Diretrizes Curriculares Nacionais para os cursos de bacharelado e licenciatura em Computação. Parecer CNE/CES 136/2012. Recuperado de http://portal.mec.gov.br/component/content/article?id=12991.

Moreira, Vera L B. (2007). Planejamento urbano em pequenos municípios: o caso do Paraná. 2007. 219 f. Dissertação (Mestrado em Urbanismo). Pontifícia Universidade Católica de Campinas. Campinas.

Nascimento, F. D. S. (2013). Expansão e interiorização das universidades federais: uma análise do processo de implementação do campus do litoral norte da Universidade Federal da Paraíba. Mestrado. Universidade Federal da Paraíba. Recuperado de https://repositorio.ufpb.br/jspui/handle/tede/3832.

Oliveira, W., França, R., Lemos, A., da Cruz, M., Scaico, P., Amaral, H., \& Teixeira, L. (2020). Os Desafios Enfrentados pela Licenciatura em Computação que a Comunidade de Educação em Computação Precisa Conhecer. In Anais do XXVIII Workshop sobre Educação em Computação, (pp. 191-195). Porto Alegre: SBC. doi:http://dx.doi.org/10.5753/wei.2020.11156.

Palmeira, L. B., \& Santos, M. P. (2014). Evasão no Bacharelado em Ciência da Computação da Universidade de Brasília: análise e mineração de dados. xvi, 127 f., il. Monografia (Bacharelado em Ciência da Computação)—Universidade de Brasília, Brasília.

Raabe, A. L. A., Brackmann, C. P., \& Campos, F. R. (2018). Currículo de referência em tecnologia e computação: da educação infantil ao ensino fundamental. Centro de Inovação para a Educação Básica-CIEB.

Rodrigues, F., Brackmann, C., \& Barone, D. (2015). Estudo da Evasão no Curso de Ciência da Computação da UFRGS. Revista Brasileira de Informática na Educação, 23(01), 97. doi:http://dx.doi.org/10.5753/rbie.2015.23.01.97.

Rodrigues, S., Aranha, E., \& Silva, T. (2018). Computação Desplugada no Ensino de Programação: Uma Revisão Sistemática da Literatura. Brazilian Symposium on Computers in Education (Simpósio Brasileiro de Informática na Educação - SBIE), 29(1), 417. doi:http://dx.doi.org/10.5753/cbie.sbie.2018.417.

SBC (2002). Currículo de Referência para Cursos de Licenciatura em Computação. GT de Licenciatura em Computação Recuperado de https://www.sbc.org.br/documentosda-sbc/summary/131-curriculos-de-referencia/763-curriculo-de-referencia-licversao-2002.

SBC (2018). Nota técnica sobre a BNCC (Ensino médio e fundamental). Recuperado de https://www.sbc.org.br/institucional-3/cartas-abertas/summary/93-cartasabertas/1197-nota-tecnica-sobre-a-bncc-ensino-medio-e-fundamental.

UFPR (2015). Projeto Pedagógico do Curso de Licenciatura em Computação. Jandaia do Sul. Recuperado de http://www.jandaiadosul.ufpr.br/licenciatura-em-computacao/.

Vasconcelos, V., \& Andrade, E. (2018). Análise da Evasão de Alunos na Licenciatura em Computação. In Anais do XXVI Workshop sobre Educação em Computação. Porto Alegre: SBC. doi:10.5753/wei.2018.3482. 